\section{Infant Feeding Patterns of HIV Positive Mothers and Disclo- sure of Status to Family and Partners in Botswana}

\section{Tshiamo Reginald Keakabetse ${ }^{1 *}$, Tebatso Paul ${ }^{1}$, Lemphi Moremi $^{1}$, Onalenna Seitio-Kgokgwe ${ }^{1}$, Thuto Tomeletso ${ }^{1}$, Rex Stockton ${ }^{2}$ and Ratanpriya Sharma ${ }^{3}$}

1 Institute for Development Management, Botswana

${ }^{2}$ Indiana University, Indiana, USA

${ }^{3}$ University of Miami, Florida, USA

\begin{abstract}
Transmission during breast feeding, which is a multifactorial process, has been associated with increased HIV transmission of $35 \%$ $45 \%$ in the developing countries. Infants who are formula fed stand a higher risk of morbidity and mortality due to other causes such as malnutrition, pneumococcal infections and diarrhoeal diseases. It is against this background that this study was conducted to assess women's decisions making process regarding PMTCT, decisions on infant feeding, infant testing and status disclosure to significant others. The results of this study will be used to develop pragmatic interventions and healthcare practices that better address the barriers to prevention of mother to child transmission of HIV while ensuring infant survival.
\end{abstract}

Keywords: Breast Feeding; HIV Positive Mothers; Malnutrition;Multifactorial process; Transmission

\section{Introduction}

Almost 98\% paediatric HIV infection occurs through mother-tochild transmission during the processes of pregnancy, childbirth or

*Corresponding author: Tshiamo Reginald Keakabetse, Department of Public Health, Institute of Development Management, 20222 Mbutho Road,Gaborone, Botswana, Tel: +267 71834676; email: tkeakabetse@idmbls.ac.bw

Citation: Keakabetse TR, Paul T, Stockton R, Ratanpriya S, Moremi L, et al. (2019) Infant Feeding Patterns of HIV Positive Mothers and Disclosure of Status to Family and Partners in Botswana. J AIDS Clin Res Sex Transm Dis 6: 027.

Received: November 15, 2019; Accepted: December 16, 2019; Published: December 23, 2019

Copyright: () 2019 Keakabetse TR, et al. This is an open-access article distributed under the terms of the Creative Commons Attribution License, which permits unrestricted use, distribution, and reproduction in any medium, provided the original author and source are credited. breastfeeding [1]. Transmission during breastfeeding, which is a multifactorial process, has been associated with increased HIV transmission of $35 \%-45 \%$ in the developing countries [2,3]. However, babies who are not breastfed stand a higher risk of morbidity and mortality due to other causes such as malnutrition, pneumococcal infections and diarrhoeal diseases. These has created a dilemma amongst HIV positive mothers on whether to breastfeed and expose babies to HIV infection or formula feed and risk their new-borns to die from other causes of mortality [4]. As observed by Chisenga choosing an infant feeding practice for HIV positive African women is quite complex [5].

Globally, infant feeding guidelines have changed rapidly overtime since HIV was discovered in breastmilk and its transmission through breastfeeding was confirmed [6-10]. This has led to confusion and non-adherence to HIV positive mothers on the mode of infant feeding. Several authors have noted that adhering to infant feeding patterns as outlined in the guidelines has remained a challenge in developing countries especially within the African context (Botswana included), where there is a high premium placed on breastfeeding $[11,12]$. With evidence linking mother to child transmission through breastfeeding, mothers have been very reluctant to opt for the option of exclusive breastfeeding. Studies done in Nairobi and Uganda both reported increased rates of HIV transmission through breastfeeding and this evidence illustrate a dilemma amongst healthcare workers and mothers regarding which method of infant feeding to promote and practice, respectively [13-15].

On the other hand, due to stigma associated with HIV infection, formula feeding has been perceived as "forced" disclosure of HIV status, as women who opted to formula feed are believed to be HIV positive. Moreover, studies have also indicated that there are other determinants that pressure women to opt for a particular infant feeding pattern. Some women have reported pressure from service providers, partners or caregivers and other socio-cultural or economic factors [16-18]. Sibeko observed that where infant formula is the recommended mode of infant feeding, it is rarely feasible in resource constraint settings due to stigma associated with formula feeding [19]. Ndubuka reiterate that AIDS related stigma poses a significant barrier to the uptake of formula feeding in Botswana, thus nullifying the government efforts of ensuring exclusive formula feeding amongst HIV positive mothers. HIV positive women who have accepted their HIV status have significantly higher knowledge of infant feeding practices and this knowledge can easily be transferred to practice.

A study by Stockton observed a tendency among women in Botswana to hide their status from significant others [20]. This lack of disclosure has a bearing on the uptake of recommended PMTCT services including patterns of infant feeding. Furthermore, the rates of infants testing have remained significantly low in Botswana. Disclosure rates to sexual partners have been found to be higher (16-86\%) for women who attend voluntary testing and counselling clinics than women tested at antenatal clinics (ANC). Amongst the ANC tested 
Citation: Keakabetse TR, Paul T, Stockton R, Ratanpriya S, Moremi L, et al. (2019) Infant Feeding Patterns of HIV Positive Mothers and Disclosure of Status to Family and Partners in Botswana. J AIDS Clin Res Sex Transm Dis 6: 027.

women, an average of $8 \%$ of women reported a violent reaction from partners upon disclosure, thus having implications on optimal uptake and adherence to infant feeding practices [21].

Botswana has had a successful PMTCT Programme with a testing uptake of $98 \%$, ART uptake of $96 \%$ and a mother-to-child transmission (MTCT) rate ranging between 3-4\% and a low testing rate (47\%) of HIV-exposed babies at 6-8 weeks old using DNA PCR [22,23]. HIV testing is routinely provided as part of antenatal care, delivery, and post-natal care services as part of the PMTCT processes. HIV prevalence among pregnant women remains high at $30.4 \%$ and a high percentage (93. 5\%) of mothers who test positive during ANC are enrolled into the PMTCT program [24,25].

In accordance with the United Nations recommendations on breastfeeding, Botswana National PMTCT Guidelines were revised and endorsed exclusive formula feeding for the first 6 months of life, with introduction of complimentary feeds thereafter provided that this option was acceptable, feasible, affordable, sustainable, and safe, commonly dubbed the AFASS criterion. To support this recommendation, the government, through the Ministry of Health, provided infant formula feeds for free for up to twelve months of life. For the HIV positive mothers who did not meet the AFASS criteria as per the guidelines, optimal breastfeeding is recommended. Optimal breastfeeding is defined as exclusive breastfeeding for the first six months of life. After the initial six months, formula feeding can be introduced at any time provided the AFASS criterion is met [26,27].

A clinical trial commonly known as the Mashi study, done by Botswana Harvard Partnership which compared the efficacy and safety of two infant feeding strategies (breastfeeding and formula feeding) in preventing postnatal mother-to-child HIV transmission has shown that infants who were in the formula-fed group had lower rates of HIV infection but increased rates of early mortality and adverse events from infectious diseases than those who were in the breastfed group. Based on the results of Mashi study, exclusive breastfeeding was regarded as the feasible method of preventing mother-to-child transmission in Botswana [28,29].

As the country moves towards implementation of option $\mathrm{B}+$ in order to eliminate MTCT of HIV, understanding of the infant feeding patterns including knowledge, attitudes and practices is crucial. It is against this background that this study was carried out to fill this knowledge gap. The study seeks to assess the infant feeding patterns of HIV positive mothers and disclosure to family or care givers in an effort to greater understand the factors which contribute to infant feeding decisions and practices.

Building on the information gathered thus far, the current study focuses on women's decisions regarding PMTCT, including decisions on infant feeding, infant testing and status disclosure to significant others. The results of this study will be used to develop pragmatic interventions and healthcare practices that better address the barriers to prevention of mother to child transmission of HIV.

\section{Methods}

\section{Study design}

The study utilized a cross sectional quantitative and qualitative methodology to assess the patterns of infant and the influence of disclosure on the different feeding choices amongst HIV positive mothers attending postnatal clinics. Results of the quantitative component have been published elsewhere [30].

\section{Population, sampling and setting}

Data was collected from 305 (quantitative) and 60 (qualitative) HIV positive women, postnatal within 6 months of delivery attending Child Welfare Clinics (CWC) in selected districts and government health facilities. Using the booking register at the respective facilities, eligible women were approached about the study and those who agreed to participate were interviewed. Eligibility criteria included: HIV positive mothers exposed to PMTCT, over 18 years old, having a live baby within 6 months post-delivery and not having any HIV defining illnesses. Purposive sampling was employed to recruit participants from randomly selected clinics from city, town, urban, and rural areas. The sites included Gaborone, Selebi Phikwe, Lobatse, Mahalapye, Boteti/Letlhakane and Ghanzi districts.

\section{Survey instrument}

A survey instrument was developed and translated to Setswana and English as these are the two national languages in Botswana. For the qualitative arm, open-ended questions were administered seeking in-depth information on participants' decisions on infant feeding, infant testing, experiences in disclosing HIV/AIDS status to partner, and the ways in which disclosure impacts feeding decisions. The survey included the following sections: socio-demographic information, baby's health, mother's health, infant feeding intentions/practices and disclosure to partner/family.

\section{Procedure}

The study was approved by the Ministry of Health in Botswana (Health Research and Development Committee). Informed consent was administered to respondents in English or Setswana based on the preference of the participant. Participants were informed of the study rationale, were assured that participation was voluntary, and were informed of the limits of confidentiality. Trained research assistants travelled to each of the selected clinic sites and explained the study and consent procedure to potential participants. Those who agreed to participate signed a consent form and the study tool administered.

\section{Data analysis}

Qualitative data were constructed into themes using basic content analysis when reading through the participants' responses. This technique has been hailed as a quick and efficient early method in qualitative data analysis [31]. From this early thematic analysis, a conceptual framework constructed and final themes were streamlined into the framework based on repeats commentary, concepts and key words derived from responses. The process of thematic analysis was conducted independently by author one and confirmation of themes through discussion with research assistants. Firstly, pre-determined themes from literature were used as the framework for content analysis and emerging issues were added to the framework following discussion and interpretation by analysis team. Initial themes that were derived from literature included health system support, negative experiences of disclosure, stigma and discrimination as some of the factors that influenced infant feeding choices [32-34]. 
Citation: Keakabetse TR, Paul T, Stockton R, Ratanpriya S, Moremi L, et al. (2019) Infant Feeding Patterns of HIV Positive Mothers and Disclosure of Status to Family and Partners in Botswana. J AIDS Clin Res Sex Transm Dis 6: 027.

\section{Findings}

Table 1 shows the demographic status of the 60 respondents in the study. The age range of the women was 15-42 years, with mean age of 32 years. Majority of the women, $53 \%(n=32)$ were in a cohabitation relationship. The mothers had high literacy with $86 \%(\mathrm{n}=52)$ having gone beyond primary level. Unemployment levels remained high at $68 \%(n=41)$.

\begin{tabular}{|c|c|c|}
\hline Age (Years) & Frequency $(\mathrm{N}=60)$ & Percentage\% \\
\hline $15-19$ & 3 & 5 \\
\hline $20-24$ & 12 & 20 \\
\hline $25-29$ & 13 & 22 \\
\hline $30-34$ & 14 & 23 \\
\hline $35-39$ & 16 & 27 \\
\hline$>40$ & 2 & 3 \\
\hline \multicolumn{3}{|l|}{ Marital status } \\
\hline Single & 22 & 37 \\
\hline Married & 5 & 8 \\
\hline Cohabiting & 32 & 53 \\
\hline Divorced & 1 & 2 \\
\hline Widowed & 0 & 0 \\
\hline \multicolumn{3}{|l|}{ Education } \\
\hline None & 2 & 3 \\
\hline Non-formal & 2 & 3 \\
\hline Primary & 5 & 8 \\
\hline Secondary & 35 & 58 \\
\hline Post-secondary & 17 & 28 \\
\hline \multicolumn{3}{|l|}{ Employment } \\
\hline Unemployed & 41 & 68 \\
\hline Salaried employed & 11 & 18 \\
\hline Casual employment & 3 & 5 \\
\hline Self-employed & 5 & 9 \\
\hline Other & 0 & 0 \\
\hline \multicolumn{3}{|l|}{ Income (Pula) } \\
\hline None & 41 & 68 \\
\hline$<1000$ & 8 & 13 \\
\hline $1000-2000$ & 4 & 7 \\
\hline $2001-3000$ & 3 & 5 \\
\hline $3001-4000$ & 3 & 5 \\
\hline $4001-5000$ & 1 & 2 \\
\hline$>5000$ & 0 & 0 \\
\hline
\end{tabular}

Table 1: Demographic characteristics.

\section{Factors influencing method choice and disclosure}

The respondents provided data on factors influencing infant feeding patterns and experiences of disclosure to family members. A variety of factors emerged from the data ranging from service provision approaches like counselling, mothers' perspectives as well as their knowledge and circumstances. Responses were categorised and presented as per the themes that follow.

\section{PMTCT counselling}

As part of routine PMTCT services, mothers receive counselling during antenatal care, delivery, and postnatal periods. Mothers were asked about factors that influence their decision to select any infant feeding method. Mothers who chose exclusive breastfeeding indicated that PMTCT counselling had a significant role in aiding them to choose the method. This was buttressed by some of excerpts from a mother who said:

"I was taught by a nurse that I can still breastfeed without passing the virus to my child..."

Mothers were given advice based on their individual conditions post assessment to guide on which method would be suitable. Based on the mothers' medical condition, service providers suggested specific infant feeding practice as one of the mothers explained:

"Because I was told to breastfeed by the Doctor as my CD4 count was high."

\section{Perceived benefits}

Decision making about the choice of infant feeding practice was also influenced by the perceptions mothers had about a particular method. Mothers who chose breastfeeding believed that the method is beneficial to the baby as it is convenient and prevents infections. The mothers indicated that:

"Baby grows well and the milk is ever ready and at correct temperature."

"Breast milk prevents poor hygiene illnesses as it is safe and clean" "Breast feeding, because it prevents the baby from short illnesses like diarrhoea"

So mothers who chose breastfeeding believed that it had a protective effect on the baby and that influence their decision making about the method of choice for infant feeding.

\section{Perceived stigma}

Mothers expressed that there is a societal expectation that they should breastfeed their babies post-delivery. They said if they choose not to breastfeed, people will know their HIV status. One mother said:

"Exclusive breastfeeding helps us in terms of stigma and no one will know if you are sick or what..."

To avoid this kind of "forced disclosure", mothers chose exclusive breastfeeding. From the mothers' perception, stigma has a role in influencing the method of infant feeding by HIV positive mothers, specifically inclination to choose exclusive breastfeeding.

\section{Fear of infecting the infant}

Understanding that transmission of HIV can occur during breastfeeding influenced mothers to consider formula feeding as a method of choice. This was expressed during conversations with mothers indicating what influenced their decision not to choose breastfeeding. Their individual responses were:

"I am scared to infect my baby..."

"I do not want to transmit the virus to the baby"

"I did not want my baby to contact the virus through breastfeeding. Formula is much safer"

\section{Mother's circumstances}

Some participants chose their index method of infant method because of their circumstances. They would have otherwise chosen a different 
Citation: Keakabetse TR, Paul T, Stockton R, Ratanpriya S, Moremi L, et al. (2019) Infant Feeding Patterns of HIV Positive Mothers and Disclosure of Status to Family and Partners in Botswana. J AIDS Clin Res Sex Transm Dis 6: 027.

method (breastfeeding) but because of their prevailing situations, they ended resorting to another method (formula feeding). This data was deduced from the following verbatim expressions from individual mothers:

\section{"Formula feeding because i started ARV late."}

"Formula feeding because I am working and I go on trips sometimes."

"...my nipples are too small so the midwife advised me to formula feed"

\section{Mother's knowledge}

Knowledge about infant feeding method practices and transmission of HIV played a role in influencing mother to opt for a particular method. Mothers who had limited information chose formula feeding either because, they did not get sufficient information or all they knew was that HIV positive mothers should not breast feed. Asked which they were on and what influenced their decision, mothers said:

"Formula feed because I have the virus."

"Formula feeding because I didn't understand or get the information properly about breastfeeding."

\section{HIV disclosure experiences}

Upon disclosure of status to significant other, parents or partners, HIV positive mothers had either positive or negative experiences. Positive experiences were reported as illustrated by the following expressions from different women:

"Accepted and encourages me on taking treatment"

"Both my partner and family were so supportive"

However, those who went through negative experiences said:

"At first the family was not supportive. They didn't care about me after I delivered the baby they showed me support, my partner was supportive"

"I have realised that people who use to be your friends will discriminate you, saying bad things about you"

It is evident from the above mothers' expressions that disclosure can enhance support through positive experiences or can bring about regretful moments if mothers receive negative experiences after disclosing their positive status.

The study explored infant testing practices, enablers and barriers as part of the PMTCT continuum. There was general anecdotal data on inadequate testing rates by HIV positive mothers hence the key question in this regard related to reasons for low uptake of the service. Mothers expressed varying causes ranging limited information on when infants should be tested, logistical challenges related to scheduling of services and infrastructural issues or lack of commodities for infant testing. Some of the reasons are supported by the following excerpts derived from the data:

"Health professionals keep sending me back home promising to call' "I am still waiting for booking date"

"I was not aware I should test her"

As clearly observed from the mothers responses, reasons for lack of infant testing were mainly facility related which provides opportunity for improvement of this service.

\section{Discussion}

The survival of HIV exposed infants is highly dependent on PMTCT interventions including infant feeding practices of HIV positive mothers. Mothers struggle with recent HIV diagnosis, challenges of caring for the baby including infant feeding and disclosing their status to significant others.HIV positive mothers should be informed about the different infant feeding modalities regardless of their preferences. While guidelines recommend the criteria of AFASS to be used to guide service providers on counselling HIV positive mothers about the method of infant feeding, it should not that the decision making process is quite complex. It should take into consideration the intricate local societal environment and the mothers' ability to withstand its influences. Poggensee reiterate that there is need for assessment of local context to implement appropriate evidence informed interventions. Data on exclusive breastfeeding in African context has been reported to be very low ranging from 17\%in Zimbabwe, 23\% in Zambia (WH), 2003 and 29\% in South Africa [35-37]. Globally, studies from Bangladesh and Brazil have shown early introduction of other feeds increases mortality due to diarrhoea and pneumonia [18]. HIV positive women in this study made decisions about infant feeding based on a variety of factors including personal circumstances and their knowledge or lack; about HIV transmission during breastfeeding. A study by Laher concluded that for the success of HIV prevention through the PMTCT service provision, a variety of individual, social and structural factors must be addressed [38].

Disclosure of HIV status to sexual partners has been identified as an important strategy towards prevention and control of HIV [39]. Despite the benefits of disclosure, some women have had negative experiences post exposure including loss of economic support, discrimination, abuse and family disruptions. However, majority of women who disclosed their status reported supportive responses from their partners and families. It is equally important to take advantage of the prevailing disclosure environment and to implement programmatic interventions. This would potentially eliminate barriers to disclosure.

Potential limitations of this study include the fact that the sample size was typically small, hence the experiences presented do not necessarily represent all HIV positive women. Moreover, we used purposive sampling method which could the mothers who participated in the study may have had similar characteristics thus their openness to share their experiences. However, participants were sought form rural and urban settings with variant socio demographics variables. We therefore believe that findings are applicable to HIV positive women with similar characteristics.

\section{Conclusions and Recommendations}

To address infant feeding practices amongst HIV positive mothers, it is imperative to use a multifaceted approach addressing socio-cultural and economic determinants of decision making amongst these women. PMTCT interventions have to be strengthened to ensure mothers receive appropriate information at the right time. Mothers should be supported together with their significant others on disclosure of HIV status. Early Infant Diagnosis (EID) remained a challenge in this study, further investigations should be considered to unravel the nuances that could be attributable to that. 
Citation: Keakabetse TR, Paul T, Stockton R, Ratanpriya S, Moremi L, et al. (2019) Infant Feeding Patterns of HIV Positive Mothers and Disclosure of Status to Family and Partners in Botswana. J AIDS Clin Res Sex Transm Dis 6: 027.

\section{Acknowledgements}

We acknowledge the contribution of Kagiso Kobedi and research assistants who were resourceful in data collection, entry and cleaning. This research project was supported by a grant from the National AIDS Coordinating Agency (NACA).

\section{References}

1. World Health Organisation, PMTCT strategic vision 2010-2015: Preventing mother-to-child transmission of HIV to reach the UNGASS and Millennium Development Goals: moving towards the elimination of paediatric HIV, December 2009.

2. De Cock KM, Fowler MG, Mercier E, Vincenzi ID, Saba J, et al. (2000) Prevention of Mother-to-Child HIV Transmission in Resource-Poor CountriesTranslating Research Into Policy and Practice. JAMA 283: 1175-1182.

3. Douglas GC, King BF (1992) Maternal-Fetal Transmission of Human Immunodeficiency Virus: A Review of Possible Routes and Cellular Mechanisms of Infection. Clin Infect Dis 15: 678-691.

4. Ndubuka J, Ndubuka N, Li Y, Marshall CM, Ehiri J, et al. (2013) Knowledge, attitudes and practices regarding infant feeding among HIV-infected pregnant women in Gaborone, Botswana: a cross-sectional survey. BMJ Open 3.

5. Chisenga M, Siame J, Baisley K, Kasonka L, Filteau S, et al. (2011) Determinants of infant feeding choices by Zambian mothers: a mixed quantitative and qualitative study. Matern Child Nutr 7: 148-159.

6. WHO, Guidelines on HIV and Infant Feeding 2010: Principles and Recommendations for Infant Feeding in the Context of HIV and a Summary of Evidence. 2010: Geneva: World Health Organization.

7. Gaillard P, Piwoz E, Farley TM (2001) Collection of standardized information on infant feeding in the context of mother-to-child transmission of HIV. Stat Med 20: 3525-3537.

8. Papathakis P, Rollins N (2004) Are WHO/UNAIDS/UNICEF-recommended replacement milks for infants of HIV-infected mothers appropriate in the South African context? Bull World Health Organ 82: 164-171.

9. Thiry L, Sprecher-Goldberger S, Jonckheer T, Levy J, Henrivaux P, et al. (1985) Isolation of AIDS virus from cell-free breast milk of three healthy virus carriers. Lancet 326: 891-892.

10. Ziegler JB, Johnson RO, Cooper DA, Gold J (1985) Postnatal transmission of AIDS-associated retrovirus from mother to infant. Lancet 325: 896-898

11. Musa J (2011) Withholding breast milk for HIV exposed infants in sub-Saharan Africa: benefit or harm? Afr Health Sci11: 602-604.

12. Oladokun RE, Brown BJ, Osinusi K (2010) Infant-feeding pattern of HIV-positive women in a prevention of mother-to-child transmission (PMTCT) programme. AIDS care 22: 1108-1114

13. Nduati R, John G, Richardson B, Overbaugh J, Mwatha, et al. (2000) Effect of breastfeeding and formula feeding on transmission of HIV-1: a randomized clinical trial. JAMA 283: 1167-1174.

14. Magoni M, Bassani L, Okong P, Kituuka P, Germinario EP, et al. (2005) Mode of infant feeding and HIV infection in children in a program for prevention of mother-to-child transmission in Uganda. Aids 19: 433-437.

15. Doherty T, Chopra M, Nkonki L, Jackson D (2006) Effect of the HIV epidemic on infant feeding in South Africa:" When they see me coming with the tins they laugh at me". Bull World Health Organ 84: 90-96.

16. Doherty T, Sanders D, Goga A, Jackson D (2011) Implications of the new WHO guidelines on HIV and infant feeding for child survival in South Africa. Bull World Health Organ 89: 62-67.
17. Chopra M, Doherty T, Mehatru S, Tomlinson M (2009)Rapid assessment of infant feeding support to HIV-positive women accessing prevention of mother-to-child transmission services in Kenya, Malawi and Zambia. Public Health Nutr 12: 2323-2328.

18. Poggensee G, Schulze K, Moneta I, Mbezi P, Harms G, et al. (2004) Infant feeding practices in western Tanzania and Uganda: implications for infant feeding recommendations for HIV-infected mothers. Trop Med Int Health 9: 477-485.

19. Sibeko L, Donald KG, Nzuza S (2009) Mothers' infant feeding experiences: constraints and supports for optimal feeding in an HIV-impacted urban community in South Africa. Public Health Nutr 12: 1983-1990.

20. Stockton R, Paul T, Morran DK, Yebei PK, Chang SH, et al. (2012) A survey of HIV/AIDS counselors in Botswana: Satisfaction with training and supervision, self-perceived effectiveness and reactions to counseling HIV-positive clients. J HIV AIDS Soc Serv 11: 424-446.

21. Medley A, Garcia-Moreno C, McGill S, Maman S (2004) Rates, barriers and outcomes of HIV serostatus disclosure among women in developing countries: Implications for prevention of mother-to-child transmission programmes. Bull World Health Organ 82: 299-307.

22. Creek T, Ntumy R, Mazhani L, Moore J, Shaffer N et al. (2009) Factors associated with low early uptake of a national program to prevent mother to child transmission of HIV (PMTCT): results of a survey of mothers and providers, Botswana, 2003. AIDS and Behavior 13: 356-364.

23. Stover J, Fidzani B, Molomo BC, Moeti T, Musuka G et al. (2008) Estimated HIV trends and program effects in Botswana. PLoS One 3.

24. Shapiro RL, Hughes MD, Ogwu A, Moyo S, Thior I, et al. (2010) Antiretroviral regimens in pregnancy and breast-feeding in Botswana. $\mathrm{N}$ Engl $\mathrm{J}$ Med 362: 2282-2294.

25. Ferrand RA, Corbett EL, Wood R, Hargrove J, Williams BG, et al. (2009) AIDS among older children and adolescents in Southern Africa: projecting the time course and magnitude of the epidemic. AIDS 23: 2039-2046.

26. Powis KM, Smeaton L, Ogwu A, Lockman S, Leidner J, et al. (2011) Effects of in utero antiretroviral exposure on longitudinal growth of HIV-exposed uninfected infants in Botswana. J Acquir Immune Defic Synd 56: 131-138.

27. Zash R, Souda S, Chen JY, Binda K, Peterson SD, et al. (2016) Reassuring birth outcomes with tenofovir/emtricitabine/efavirenz used for prevention of mother to child transmission of HIV in Botswana. J Acquir Immune Defic Syndr 71: 428-436.

28. Thior I, Lockman S, Smeaton LM, Wester C, Heymann SJ, et al. (2006) Breastfeeding plus infant zidovudine prophylaxis for 6 months vs formula feeding plus infant zidovudine for 1 month to reduce mother-to-child HIV transmission in Botswana: a randomized trial: the Mashi Study. JAMA 296: 794-805.

29. Shapiro RL, Kitch D, Ogwu A, Hughes MD, Essex M, et al. (2013) HIV transmission and 24-month survival in a randomized trial of HAART to prevent MTCT during pregnancy and breastfeeding in Botswana (The Mma Bana Study). AIDS 27:1911.

30. Stockton R, Paul T, Moremi L, Seitio-Kgokgwe O, Pardue DA, et al. (2018) Survey of HIV mothers in Botswana: Feeding methods, support, status disclosure and infant testing. J Pregnancy and Reprod 2: 1-8.

31. Ryan GW, Bernard HR (2003) Techniques to identify themes. Field methods 15: 85-109.

32. Sibeko LN, (2007) Acceptability and Feasibility of Heat-treated Expressed Breastmilk Following Exclusive Breastfeeding by HIV-1 Infected South African Women. McGill University. 
Citation: Keakabetse TR, Paul T, Stockton R, Ratanpriya S, Moremi L, et al. (2019) Infant Feeding Patterns of HIV Positive Mothers and Disclosure of Status to Family and Partners in Botswana. J AIDS Clin Res Sex Transm Dis 6: 027.

- Page 6 of 7 •

33. Ssali SN, Atuyambe L, Tumwine C, Nannungi A, Srgujja E, et al. (2010) Reasons for disclosure of HIV status by people living with HIV/AIDS and in HIV care in Uganda: an exploratory study. AIDS Patient Care STDS 24: $675-681$.

34. Rollins N, Chanza H, Chimbwandira F, Eliya M, Nyasulu I, et al. (2014) Prioritizing the PMTCT implementation research agenda in 3 African countries: INtegrating and Scaling up PMTCT through Implementation REsearch (INSPIRE). J Acquir Immune Defic Syndr 67: 108-113.

35. Coutsoudis A, Coovadia HM, Wilfert CM (2008) HIV, infant feeding and more perils for poor people: new WHO guidelines encourage review of formula milk policies. Bull World Health Organ 86: 210-214.

36. Coutsoudis A, Kindra G, Esterhuizen T (2011) Impact of cotrimoxazole prophylaxis on the health of breast-fed, HIV-exposed, HIV-negative infants in a resource-limited setting. Aids 25: 1797-1799.
37. Coutsoudis A, Coovadia HM, Kindra G (2010) Time for new recommendations on cotrimoxazole prophylaxis for HIV-exposed infants in developing countries? Bull World Health Organ 88: 949-950.

38. Laher F, Cescon A, Lazarus E, Kaida A, Makongoza M, et al. (2012) Conversations with mothers: exploring reasons for prevention of mother-tochild transmission (PMTCT) failures in the era of programmatic scale-up in Soweto, South Africa. AIDS Behav 16: 91-98.

39. World Health Organization (2012) World Health Organization global strategy for the surveillance and monitoring of HIV drug resistance. 


\section{Hit}

Journal of Anesthesia \& Clinical Care

Journal of Addiction \& Addictive Disorders

Advances in Microbiology Research

Advances in Industrial Biotechnology

Journal of Agronomy \& Agricultural Science

Journal of AIDS Clinical Research \& STDs

Journal of Alcoholism, Drug Abuse \& Substance Dependence

Journal of Allergy Disorders \& Therapy

Journal of Alternative, Complementary \& Integrative Medicine

Journal of Alzheimer's \& Neurodegenerative Diseases

Journal of Angiology \& Vascular Surgery

Journal of Animal Research \& Veterinary Science

Archives of Zoological Studies

Archives of Urology

Journal of Atmospheric \& Earth-Sciences

Journal of Aquaculture \& Fisheries

Journal of Biotech Research \& Biochemistry

Journal of Brain \& Neuroscience Research

Journal of Cancer Biology \& Treatment

Journal of Cardiology: Study \& Research

Journal of Cell Biology \& Cell Metabolism

Journal of Clinical Dermatology \& Therapy

Journal of Clinical Immunology \& Immunotherapy

Journal of Clinical Studies \& Medical Case Reports

Journal of Community Medicine \& Public Health Care

Current Trends: Medical \& Biological Engineering

Journal of Cytology \& Tissue Biology

Journal of Dentistry: Oral Health \& Cosmesis

Journal of Diabetes \& Metabolic Disorders

Journal of Dairy Research \& Technology

Journal of Emergency Medicine Trauma \& Surgical Care

Journal of Environmental Science: Current Research

Journal of Food Science \& Nutrition

Journal of Forensic, Legal \& Investigative Sciences

Journal of Gastroenterology \& Hepatology Research

Journal of Gerontology \& Geriatric Medicine
Journal of Genetics \& Genomic Sciences

Journal of Hematology, Blood Transfusion \& Disorders

Journal of Human Endocrinology

Journal of Hospice \& Palliative Medical Care

Journal of Internal Medicine \& Primary Healthcare

Journal of Infectious \& Non Infectious Diseases

Journal of Light \& Laser: Current Trends

Journal of Modern Chemical Sciences

Journal of Medicine: Study \& Research

Journal of Nanotechnology: Nanomedicine \& Nanobiotechnology

Journal of Neonatology \& Clinical Pediatrics

Journal of Nephrology \& Renal Therapy

Journal of Non Invasive Vascular Investigation

Journal of Nuclear Medicine, Radiology \& Radiation Therapy

Journal of Obesity \& Weight Loss

Journal of Orthopedic Research \& Physiotherapy

Journal of Otolaryngology, Head \& Neck Surgery

Journal of Protein Research \& Bioinformatics

Journal of Pathology Clinical \& Medical Research

Journal of Pharmacology, Pharmaceutics \& Pharmacovigilance

Journal of Physical Medicine, Rehabilitation \& Disabilities

Journal of Plant Science: Current Research

Journal of Psychiatry, Depression \& Anxiety

Journal of Pulmonary Medicine \& Respiratory Research

Journal of Practical \& Professional Nursing

Journal of Reproductive Medicine, Gynaecology \& Obstetrics

Journal of Stem Cells Research, Development \& Therapy

Journal of Surgery: Current Trends \& Innovations

Journal of Toxicology: Current Research

Journal of Translational Science and Research

Trends in Anatomy \& Physiology

Journal of Vaccines Research \& Vaccination

Journal of Virology \& Antivirals

Archives of Surgery and Surgical Education

Sports Medicine and Injury Care Journal

International Journal of Case Reports and Therapeutic Studies

Submit Your Manuscript: http://www.heraldopenaccess.us/Online-Submission.php 